\title{
Underground Fire Service Mains
}

Underground fire service mains can be made of a variety of materials, including cast iron, ductile iron, steel, asbestos cement, plastics such as PVC, and fiber-reinforced composites. Modern cast-iron, ductile-iron, and steel pipe is normally cement lined.

A Hazen-Williams " $C$ " of 150 can be used for plastic pipe. Unlined cast-iron pipe is considered to have a " $C$ " of 100 . All cement-lined pipe is considered to have a " $C$ " of 140 .

The internal diameters of the different types of pipe vary considerably and, of course, the internal diameter is raised to the 4.87 power in the Hazen-Williams equation, which greatly magnifies the effect of the different diameters. Nominal 8 -in. asbestos cement pipe may have an internal diameter of 7.85 in., whereas nominal 8-in. Class 52 cement-lined ductile iron pipe may have an internal diameter of 8.265 in., which means that, although both pipes can be considered to have a " $C$ " of 140 , the friction loss in the asbestos cement pipe will be $28.5 \%$ greater than in the Class 52 ductile iron pipe. And we have not selected the extremes.

Many submissions of calculated sprinkler systems contain no information on the underground pipe. They usually do show an internal diameter for the underground in their calculations, and you are expected to accept it on faith. Generally, however, the friction loss in the underground in question does not exceed a few psi, making even a substantial percentage error fairly insignificant. For this reason, in the absence of specific information, we see no objection to simply plugging in the nominal pipe diameter. Only in the rare case where the loss is significant is it necessary to make an effort to ascertain the correct inside diameter. Refer to Table 4 in Appendix A for friction-loss constants based upon the nominal diameter and a Hazen-Williams " $C$ " of 140 . 